\title{
Fluidized bed calcination of cement raw meal: Laboratory experiments and CPFD simulations
}

\author{
Nastaran Ahmadpour Samani ${ }^{1}$ Chameera K. Jayarathna ${ }^{2}$ Lars-Andre Tokheim ${ }^{3}$ \\ ${ }^{1}$ Department of Process, Energy and Environmental Technology, University of South-Eastern Norway, \\ 222129@student.usn.no \\ ${ }^{2}$ SINTEF Industry, chameera. jayarathna a sintef . no \\ ${ }^{3}$ Department of Process, Energy and Environmental Technology, University of South-Eastern Norway, \\ Lars.A. Tokheimeusn. no
}

\begin{abstract}
The chemical and thermal processes associated with the decarbonation and fuel combustion in the cement kiln process produce a large amount of carbon dioxide $\left(\mathrm{CO}_{2}\right)$ contributing with around $8 \%$ of the global $\mathrm{CO}_{2}$ emissions. Utilizing green electricity instead of fossil fuels to decarbonate the raw meal in the calciner can eliminate the $\mathrm{CO}_{2}$ emissions produced through fuel combustion and also provide a basis for simple capture of the $\mathrm{CO}_{2}$ generated through calcination because $\mathrm{CO}_{2}$ is the only gaseous product exiting from the electrified calciner. In the current work, an electrically heated fluidized bed $(\mathrm{FB})$ reactor is being developed to calcine the raw meal. The FB may replace the traditional entrainment calciner used in many plants. The purpose is to enable efficient indirect heat transfer in the bubbling bed and hence obtain pure $\mathrm{CO}_{2}$ as the gaseous product from the calciner. The minimum fluidization velocity and pressure drop of the particle bed are important characteristics in the design of a bubbling fluidized bed, and these have been measured in a coldflow lab-scale fluidized bed unit with a bed height of $0.21 \mathrm{~m}$ and a circular cross-sectional area of $55 \mathrm{~cm}^{2}$. The particle size distribution of the meal ranged from $0.2-$ $180 \mu \mathrm{m}$, with a median particle size of $21 \mu \mathrm{m}$. The experimental results revealed that the regular cement raw meal is difficult to fluidize due to the large fraction of Geldart C particles in the meal (approximately 60\%). Based on experimental observation, this may be explained by inter-particular electrostatic forces forming particle clusters. The fluidization process has also been simulated with the commercial computational particle and fluid dynamics (CPFD) software Barracuda ${ }^{\circledR}$ (version 17.4.1). The purpose of using CPFD was to be able to simulate the process at coldflow conditions and then, based on this, simulate the process at large-scale hot-flow conditions. The simulation results complied quite well with the lab-scale experiments and confirmed the difficult fluidization of the meal.
\end{abstract}

Keywords: bubbling fluidized bed, calciner, electrification, CPFD, Barracuda, Geldart C, limestone

\section{Introduction}

Cement is a key constituent in concrete, the most widely used building material in the world. The cement industry is one of the main contributors to climate change by producing $8 \%$ of the global $\mathrm{CO}_{2}$ emissions. Hence, strict carbon capture mitigation strategies are needed in the cement industry to comply with the Paris agreement on climate change.

Clinker is the main constituent in cement, and in the clinker production process, there are two major contributions to emissions of $\left.\mathrm{CO}_{2}: 1\right)$ The raw meal contains typically $75-80 \%$ calcium carbonate $\left(\mathrm{CaCO}_{3}\right)$, and during the calcination of the raw meal, $\mathrm{CaCO}_{3}$ will decompose into lime $(\mathrm{CaO})$ and $\mathrm{CO}_{2}: \mathrm{CaCO}_{3} \rightarrow \mathrm{CaO}+$ $\mathrm{CO}_{2}$. In a modern cement kiln, the calcination process typically contributes to $65 \%$ of the $\mathrm{CO}_{2}$ emissions. 2) As the calcination is an endothermic process, fuel combustion is used to provide thermal energy, contributing to about $35 \%$ of $\mathrm{CO}_{2}$ emissions (Andrew, 2018; Tokheim et al., 2019).

Utilizing green electricity instead of fossil fuels to decarbonate the raw meal in the cement kiln process can eliminate the $\mathrm{CO}_{2}$ emissions produced through fuel combustion and also provide a basis for simple capture of the $\mathrm{CO}_{2}$ generated through calcination, as $\mathrm{CO}_{2}$ is the only gaseous product exiting from the electrified calciner (Tokheim et al., 2019).

Different reactors can be used as an electrified calciner. A bubbling fluidized bed (BFB) provides good mixing, hence giving efficient heat transfer and good temperature control. The BFB may operate with almost isothermal conditions, and the thermal reservoir provided by the bed prevents abrupt process changes. Hence, an electrically heated bubbling fluidized bed reactor is used to calcine the raw meal in the current study.

The BFB will replace the traditional entrainment calciner used in many cement plants. The purpose is to 
enable efficient indirect heat transfer in the bubbling bed and hence obtain pure $\mathrm{CO}_{2}$ as the gaseous product from the calciner.

\section{Methods}

In order to design an electrically heated BFB reactor to calcine the raw meal, two approaches have been combined: 1) Lab-scale experiments have been performed in order to determine some key design variables for the BFB. 2) CPFD simulations have been used to simulate the process in the lab-scale unit. The experimental part is further described in section 4, whereas the simulation part is described in section 5 .

\section{Theoretical considerations}

Raw meal from Norcem Brevik (a Norwegian cement plant) was used as the basis for the experiments, simulations, and design work. The meal had a particle size distribution ranging from 0.2 to $180 \mu \mathrm{m}$ and a median particle size of $21 \mu \mathrm{m} .59 \%$ of the particles were below $30 \mu \mathrm{m}$, i.e. being Geldart $\mathrm{C}$ particles (Kunii and Levenspiel, 2013), whereas $30 \%$ and $11 \%$ were Geldart $\mathrm{A}$ and $\mathrm{B}$ particles, respectively.

Geldart C particles are difficult to fluidize and tend to grow as a plug of particles. When exposed to the fluidization gas, cracks, channels, or so-called rat holes are formed, and the particles are not properly fluidized, especially if the diameter of the bed is large. The fluidization behavior of Geldart $\mathrm{C}$ powders is due to the vigorous inter-particle forces. When the surface-tovolume ratio of the particles increases, the interparticle forces get larger, and consequently the distance between the particles is reduced. The cohesive forces become greater than the particle gravity and the hydrodynamic forces applied by fluidization gas around the particle (Kunii and Levenspiel, 2013; Chen et al., 2009).

With a larger particle size, it could have been possible to fluidize the meal well. However, use a coarser meal is not an option as small particles are required to obtain the right clinker quality.

One of the approaches that can be applied to facilitate fluidization of Geldart $\mathrm{C}$ particles is mixing them with Geldart B particles. According to Kunii and Levenspiel (Kunii and Levenspiel, 2013), "One way of processing these solids is to introduce them into a bed of the same material but of larger size, preferably Geldart B. Even though the fines are very small, they are not entrained immediately but may stay in the bed an average of several minutes. This usually is long enough for a physical or chemical transformation of these solids."
Since the meal does contain some Geldart B (and A) particles, the experimental tests have been applied to test the flowability of the meal.

\section{Experimental work}

To investigate the fluidizability of the raw meal of limestone particles, some tests have been conducted by a cold-flow lab-scale fluidized bed unit.

\subsection{Experimental procedure}

Figure 1 shows a cold-flow lab-scale fluidized bed unit with a height of $1.5 \mathrm{~m}$ and a circular cross-sectional area of $55 \mathrm{~cm}^{2}$. The gas flow rate is controlled by the mass flow rate controller, and the pressure is measured by pressure transmitters mounted at different axial positions in the cylinder wall (P1 to P9). The distance between two adjacent transmitters is $10 \mathrm{~cm}$. The pressure and volume flow rates are recorded through a LabVIEW program.

Table 1 shows some key experimental data.

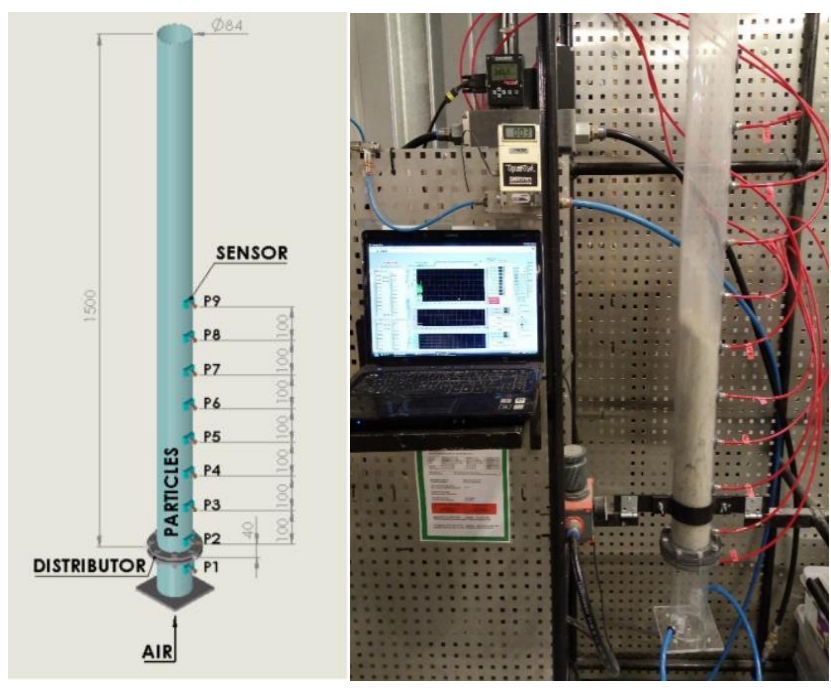

Figure 1. Cold flow lab-scaled fluidized bed unit.

Table 1: Experimental data (fluidization air properties taken from (Incropera et al., 2006)).

\begin{tabular}{|l|l|}
\hline Total bed height & $1.5 \mathrm{~m}$ \\
\hline Bed diameter & $84 \mathrm{~mm}$ \\
\hline Particle size & $0.2-180 \mu \mathrm{m}$ \\
\hline Median particle size & $21 \mu \mathrm{m}$ \\
\hline Particle density & $2795 \mathrm{~kg} / \mathrm{m}^{3}$ \\
\hline Initial dense bed height & $0.21 \mathrm{~m}$ \\
\hline Air density & $1.1707 \mathrm{~kg} / \mathrm{m}^{3}$ \\
\hline Air viscosity & $1.836 \cdot 10^{-5} \mathrm{~Pa} \cdot \mathrm{s}$ \\
\hline
\end{tabular}

\subsection{Experimental results}

As described above, close to 60 percent of particles belong to the cohesive Geldart $\mathrm{C}$ powder, and Figure 2 indeed confirms that proper fluidization does not occur. When the gas flow rate is increased, rat holes and cracks 
are formed, and the particles are not fluidized. Instead, the particles have a tendency to form clusters of particles probably due to electrostatic forces, and the particleparticle interactions prevent proper fluidization. Ratholes and channeling effects are observed in the figures. The higher the superficial gas velocity, the higher number of rat holes. With increasing gas velocity, the height of the bed is almost doubled. At high gas flow rates, a significant fraction of the particles is entrained and leave the cylinder, whereas larger particles at the bottom of the bed form clusters. Consequently, in order to fluidize this particle size distribution of raw meal, other methods should be applied.

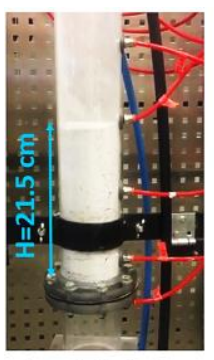

a) $v=0.024 \mathrm{~m} / \mathrm{s}$

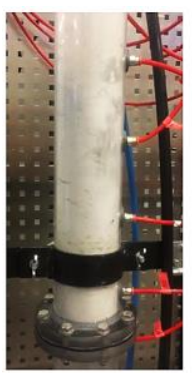

e) $\mathbf{v}=0.073 \mathrm{~m} / \mathrm{s}$

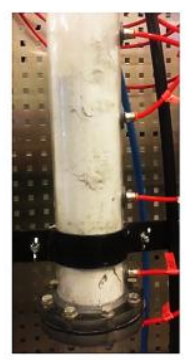

b) $v=0.048 \mathrm{~m} / \mathrm{s}$

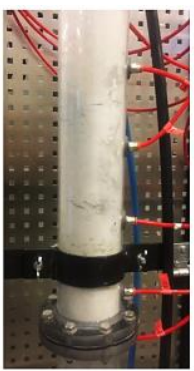

f. $v=0.079 \mathrm{~m} / \mathrm{s}$

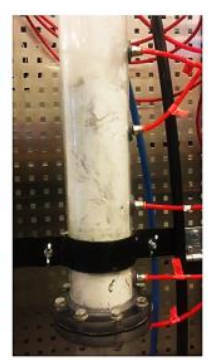

c) $\mathbf{v}=0.06 \mathrm{~m} / \mathrm{s}$

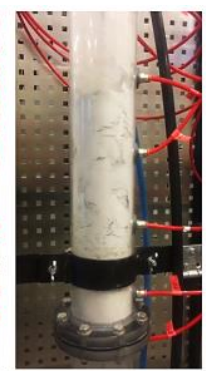

g. $v=0.085 \mathrm{~m} / \mathrm{s}$

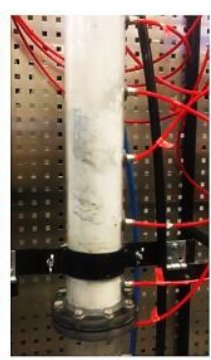

d) $\mathrm{v}=0.067 \mathrm{~m} / \mathrm{s}$

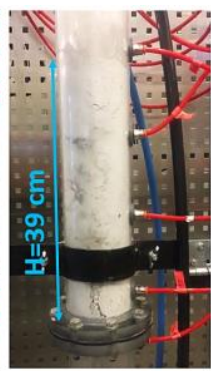

h. $v=0.091 \mathrm{~m} / \mathrm{s}$
Figure 2. Snapshots from experimental tests with different superficial gas velocities

A diagram of pressure drop over the bed versus superficial gas velocity is shown in Figure 3. Since the fluidization did not happen in the bed, the minimum fluidization velocity could not be determined experimentally by this diagram. According to the observations, rat holes are starting to form when the superficial gas velocity reaches $0.036 \mathrm{~m} / \mathrm{s}$, which explains the pressure drop decline.

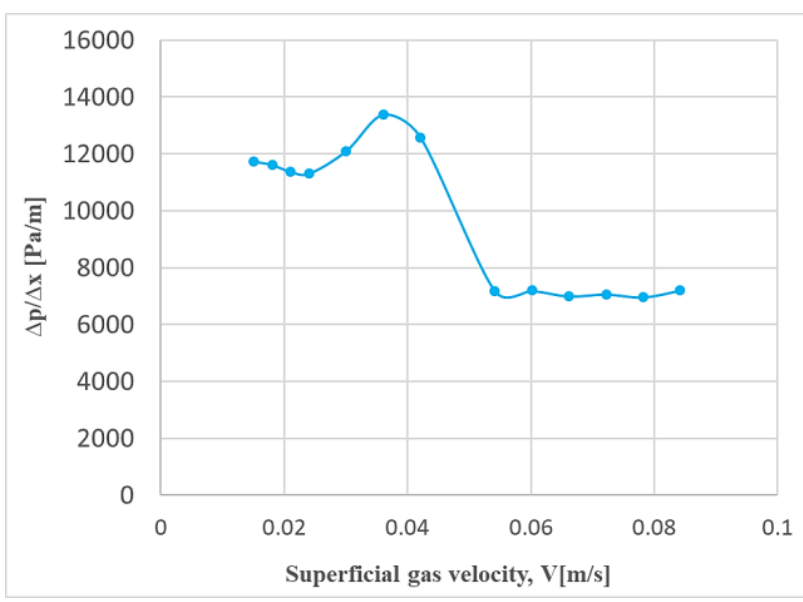

Figure 3. Experimental results for pressure drop vs superficial gas velocity.

\section{Simulations}

Computational Particle Fluid Dynamics (CPFD) modelling is applied to simulate the experimental system, aiming at finding consistency between the experimental results and the simulation results.

\subsection{The CPFD method}

CPFD is a numerical method based on the EulerianLagrangian method to simulate a large-scale multiphase (particle-fluid) flow system in three dimensions by adopting the multiphase particle-in-cell (MP-PIC) method and the particle parceling algorithm (Andrews and O'Rourke, 1996; Snider and O'Rourke, 2011). The Eulerian-Lagrangian method uses a continuum model for the fluid phase and a Lagrangian method is applied for the particle phase. This gives an appropriate numerical solution for a wide range of particle sizes, shapes, and velocities. The Navier-Stokes equation with coupling between the discrete particles is applied for the fluid phase. The direct element method (DEM) fits into the Lagrangian method to solve the particle phase (Chen et al., 2013; Jiang et al., 2014).

\subsection{Simulation set-up}

In this project, to find the minimum fluidization velocity as the main characteristic of the design of bubbling fluidized bed reactor, the flow of particles in a bubbling fluidized bed has been simulated with different flow rates. The goal is to be able to simulate the physical process at cold-flow conditions and, based on this, be able to use the CPFD model to simulate an upscaled high-temperature calcination process and hence predict the behavior of the full-scale process.

A computer-aided design (CAD) model of the BFB geometry with a stereolithography (STL) format has been prepared by applying SolidWorks.

Grid generation is the base for all simulations since it determines the spatial resolution for calculating the flow properties of the particle-gas flow. The resolution 
should be sufficiently high, so that the particle-fluid dynamics can be calculated with sufficient accuracy. However, increasing the number of cells leads to an increase in the time of the calculation. Hence, a suitable trade-off between accuracy and simulation time should be found. Besides, to achieve a stable and efficient simulation, having close to uniform cell sizes in the grid is important. Figure 4 illustrates the generated grid on the model.

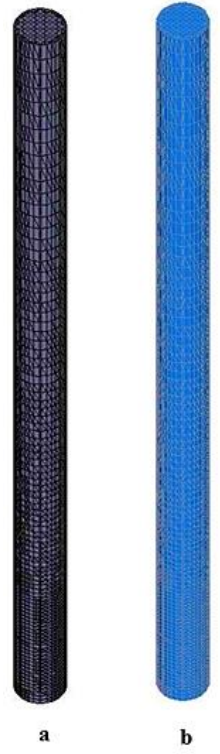

Figure 4. (a) Grid and original CAD geometry and (b) Original model geometry

The drag force $\left(F_{p}\right)$ acting on a particle through a fluid flow can be calculated by equation (1). In this equation, $m_{p}$ is the particle mass, $u_{f}$ is the fluid velocity, $u_{p}$ is the particle velocity and $D$ is a drag function, shown in equation (2).

$$
\begin{aligned}
& F_{p}=m_{p} D\left(u_{f}-u_{p}\right) \\
& D=\frac{3}{8} C_{d} \frac{\rho_{f}\left(u_{f}-u_{p}\right)}{\rho_{p} r_{p}}
\end{aligned}
$$

There are several drag models in Barracuda, and each of them provides specific correlations for the drag coefficient, $C_{d}$. The Wen-Yu drag model is appropriate for the dilute systems, and equation (3) shows the correlation for $C_{d}$ as a function of Reynolds number (equation (4)). $\theta_{f}$ is the fluid volume fraction.

$$
C_{d}=\left\{\begin{array}{cc}
\frac{24 \theta_{f}^{n_{0}}}{R e} & R e<0.5 \\
\left(C_{d}\right)_{1} & 0.5 \leq R e \leq 1000 \\
c_{2} \theta_{f}^{n_{0}} & R e>10000
\end{array}\right.
$$

$$
\begin{gathered}
R e=\frac{2 \rho_{f} r_{p}\left|u_{f}-u_{p}\right|}{\mu_{f}} \\
\left(C_{d}\right)_{1}=\frac{24}{R e} \theta_{f}^{n_{0}}\left(c_{0}+c_{1} R e^{n_{1}}\right)
\end{gathered}
$$

The model constants are:

$$
\begin{gathered}
c_{0}=1.0, c_{1}=0.15, c_{2}=0.44, n_{0}=-2.65 \text { and } \\
n_{1}=0.687
\end{gathered}
$$

The Ergun model, shown in equation (6), is suitable for higher packing fractions. The Wen-Yu/Ergun blend drag model is a combination of the Wen-Yu and Ergun drag models and can be applied for dilute as well as dense systems.

$$
D=0.5\left(\frac{c_{1} \theta_{p}}{\theta_{f} R e}+c_{0}\right) \frac{\rho_{f}\left|u_{f}-u_{p}\right|}{r_{p} \rho_{p}}
$$

Here, $c_{0}=2$ and $c_{1}=180$ (Barracuda Virtual Reactor user manual, 2017).

Approximately $60 \%$ of the raw meal particles belong to Geldart $\mathrm{C}$, and there is not any specific drag model recommended for this group of particles (Jayarathna et al., 2014; Jayarathna et al., 2017). However, the Wen-Yu drag model was used to simulate different cases in the current study.

Figure 5 shows the initial condition (a) and the boundary conditions (b). The initial height of limestone particles was set to $21 \mathrm{~cm}$. In Figure 5 (b), the inlet flow position, and the outflow position have been specified with red and yellow colours, respectively.

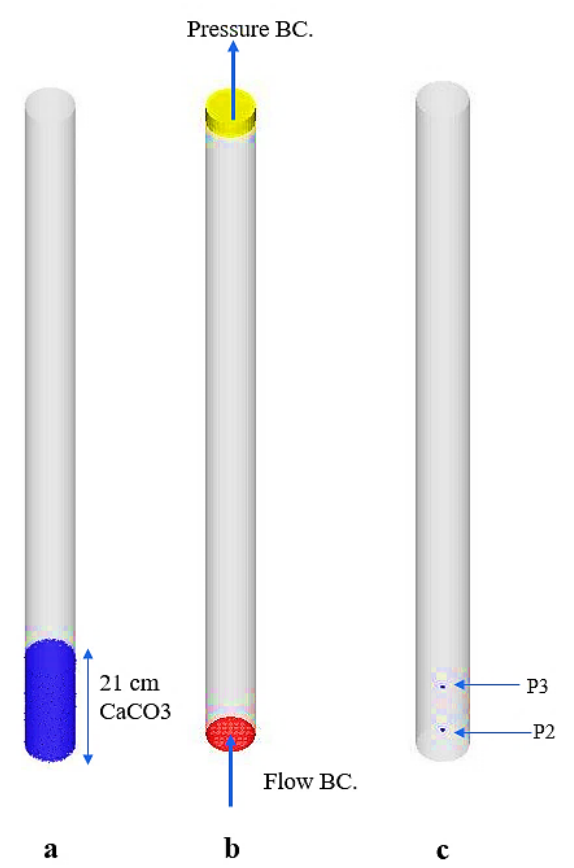

Figure 5. Initial condition (a), boundary condition (b) and transient points (c) 
The time step should be chosen so as to achieve pseudo-steady-state conditions as well as give reasonable total calculation time. To make sure that (pseudo) steady-state conditions would be reached, based on experience, and also including a safety factor, the simulations were conducted for $60 \mathrm{~s}$ of process time for all cases.

For data exploration and analysis, flux planes may be defined and transient data from the simulations can be saved in text files. The date in the text files provide a basis for comparison between simulations and experimental data. As can be seen in Figure 5 (c), transient points were determined in the positions of $\mathrm{P} 2$ and $\mathrm{P} 3$ pressure transmitters. By using the text files and collecting the value of pressures in the two positions, the minimum fluidization velocity can be calculated.

\subsection{Simulation results and comparison with experimental results}

The simulation results for ambient temperature and a velocity equal to $0.08 \mathrm{~m} / \mathrm{s}$ are presented in Figure 6. A diagram of pressure drop versus superficial gas velocity was also plotted, see Figure 7. The figure indicates that the simulation results comply well with the experimental data. After increasing the air velocity, it does penetrate into the bed, and the pressure drop increases. However, with rathole formation, the pressure drop starts to decrease. The figures illustrate that a pseudo-steady-state condition is obtained after around 20 seconds, hence demonstrating that the selected superficial gas velocity is likely adequate.

Both experimental results and simulations reveal that the fine Geldart $\mathrm{C}$ particles cannot be fluidized by conventional methods of fluidization. Other methods may be applied in order to fluidize this group of particles, such as mixing with coarse (Geldart B) particles, using flow conditioners, mechanical vibration, sound-assisted fluidization, fluidization with magnetic/electric fields, pulse fluidization, or centrifugal fluidization (Kristensen and Schaefer, 1987; Chen et al., 2009; Parikh, 2016)
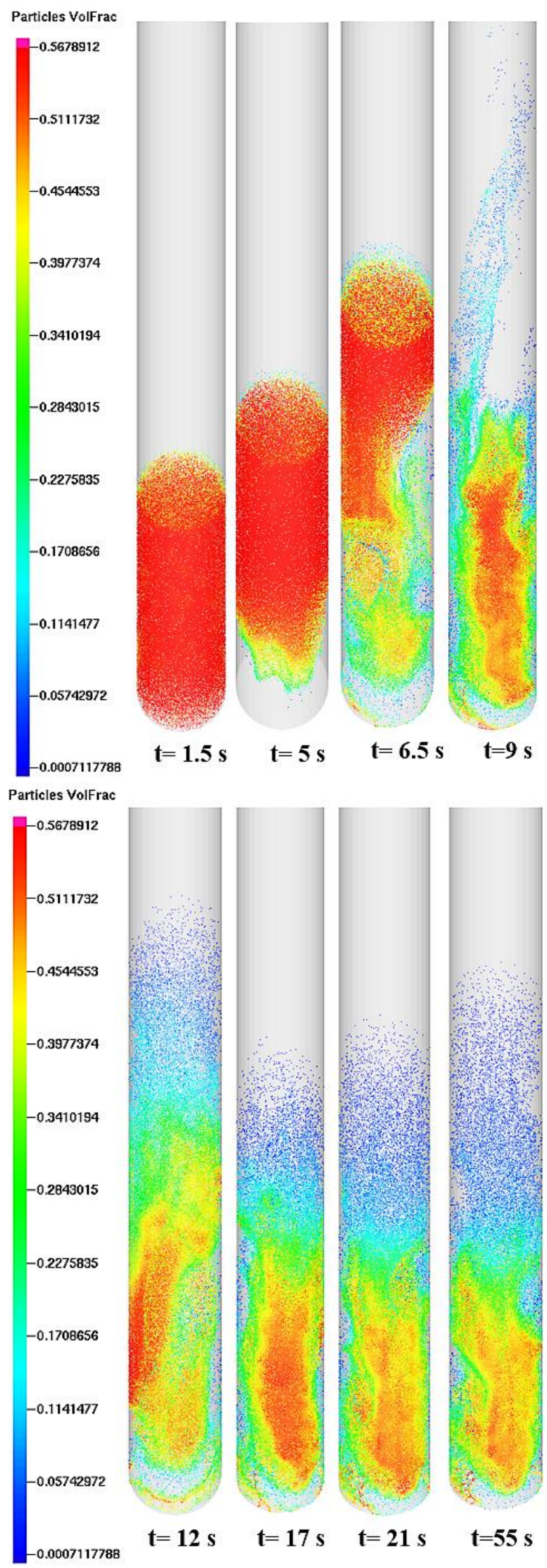

Figure 6. Simulation results of particle volume fraction of limestone 


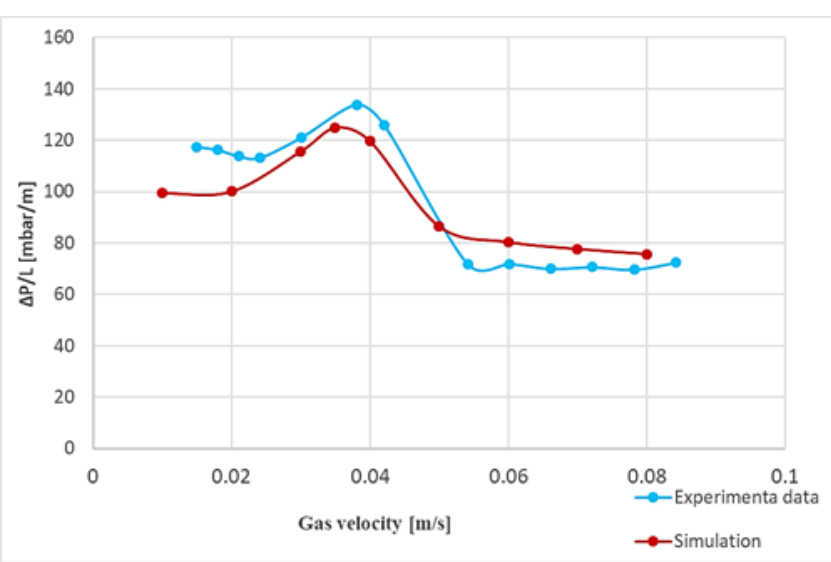

Figure 7. The pressure drop versus velocity for experimental and simulation results.

\section{Discussion}

According to (Geldart, 1973; Kunii and Levenspiel, 2013; Ram, 2013), due to the large inter-particular forces between Geldart $\mathrm{C}$ particles, they are difficult to fluidize. The results of experiments and simulations confirmed this. Therefore, although the meal of limestone consists of Geldart A and B, the fine powders of Geldart $\mathrm{C}$ have dominated the meal (approximately $60 \%$ of the meal) and there are not enough large particles to give a significant improvement in fluidization.

The minimum fluidization velocities of larger particles $(120-500 \mu \mathrm{m})$ have previously been calculated by Barracuda simulations and determined in experiments (Jayarathna et al., 2014) and showed reasonably good agreement with each other and with other literature data (Yang et al., 2004). The deviation between simulated and measured data varies between $1 \%$ and $15 \%$, and the root means the square error is $10 \%$. These studies indicated that fluidization is much easier for Geldart A and B particles.

One of the approaches that can be applied to improve the flowability of Geldart $\mathrm{C}$ particles is mixing them with a large fraction of Geldart B particles, as explained in the literature (Kunii and Levenspiel, 2013) and as shown in experiments with small limestone particles (Tashimo et al., 1999; Kato, 1991).

\section{Conclusion}

Although there were some fractions of larger particles of Geldart A and B in the raw meal, the results of the experiments of the cold-flow lab-scale BFB unit revealed that regular cement raw meal is difficult to fluidize. This is likely due to the large fraction of Geldart C particles in the meal (approximately 60\%). Owing to the fine particle sizes of the raw meal, there are strong cohesive forces between the particles, and this prevents fludization.
The results confirm the results published in the literature about Geldart $\mathrm{C}$ particles. Hence, a conventional bubbling fluidized bed is difficult to fluidize Geldart C particles. The pressure drop profile and the minimum fluidization velocity determined by CPFD simulation compared quite well with the experimental results (RMSE $10 \%$ ).

In future work, the mixing of the cement raw meal and a rather high fraction of inert Geldart $B$ particles will be investigated to find out whether this could be a way to solve the fluidization problem of the regular cement raw meal.

\section{References}

R. M. Andrew. Global CO2 emissions from cement production. Earth Syst. Sci. Data. 10: 195-217, 2018.

M. J. Andrews and P. J. O'Rourke. The multiphase particlein-cell (MP-PIC) method for dense particulate flows. International Journal of Multiphase Flow, 22: 379-402. 1996.

C. Chen, W. Joachim, H. Stefan, Q. Hai Y, and H. ErnstUlrich. CPFD simulation of circulating fluidized bed risers, Powder technology, 235: 238-47, 2013.

Y. Chen, J. Yang, R. N. Dave, and R. Pfeffer. Granulation of cohesive Geldart group $\mathrm{C}$ powders in a Mini-Glatt fluidized bed by pre-coating with nanoparticles, Powder technology, 191: 206-17. 2009.

Barracuda Virtual Reactor user manual. Houston, USA, 2017. https://cpfd-software.com

D. Geldart. Types of gas fluidization, Powder technology, 7: 285-92, 1973.

F. P. Incropera, D. P. DeWitt, T. L. Bergman, and A. S. Lavine. Fundamentals of Heat and Mass Transfer, Sixth edn John Wiley and Sons, New Jersey, USA, 2006.

C. K. Jayarathna, B. M. Halvorsen, and L. A. Tokheim. Experimental and theoretical study of minimum fluidization velocity and void fraction of a limestone based CO2 sorbent, Energy Procedia, 63: 1432-45. 2014.

C. K. Jayarathna, B. M. Moldestad, and L. A. Tokheim. Validation of results from Barracuda ${ }^{\circledR}$ CFD modelling to predict the minimum fluidization velocity and the pressure drop of Geldart A particles, Proceedings of the 58th SIMS September 25th - 27th, Reykjavik, Iceland, 2017. doi: 10.3384/ecp1713876.

Y. Jiang, G. Qiu, and H. Wang. Modelling and experimental investigation of the full-loop gas-solid flow in a circulating fluidized bed with six cyclone separators, Chemical engineering science, 109: 85-97, 2014.

K. Kato. Residence time distribution of fine particles in a powder-particle fluidized bed, Kagaku Kogaku Ronbunshu, 17: 970-75, 1991.

H. Kristensen and T. Schaefer. Granulation: a review on pharmaceutical wet-granulation, Drug development and industrial pharmacy, 13: 803-72, 1987.

D. Kunii and O. Levenspiel. Fluidization engineering, Elsevier, 2013.

D. M. Parikh, Handbook of pharmaceutical granulation technology, CRC Press, 2016.

D. K. Ram. The determination of minimum bubbling velocity, minimum fluidization velocity and fluidization index of fine powders (hematite) using gas-solid tapered beds, 
International Journal of Science and Research, 2: 287-93, 2013.

D. M. Snider and P. J. O'Rourke. The multiphase particle-incell (MP-PIC) method for dense particle flow. Computational Gas-Solids Flows and Reacting Systems: Theory, Methods and Practice (IGI Global), 2011.

T. Tashimo, T. Suto, J. Murota, and K. Kato. Calcination of fine limestone particles by a powder-particle fluidized bed, Journal of chemical engineering of Japan, 32: 374-78, 1999.

L. A. Tokheim, A. Mathisen, L. E. Øi, Ch. Jayarathna, N. H. Eldrup, and T. Gautestad. Combined calcination and $\mathrm{CO} 2$ capture in cement clinker production by use of electrical energy. In TCCS-10. CO2 Capture, Transport and Storage. Trondheim 17th-19th June 2019. Selected papers from the 10th International Trondheim CCS Conference. SINTEF Academic Press, 2019.

N. Yang, W. Wang, W. Ge, L. Wang, and J. Li. Simulation of heterogeneous structure in a circulating fluidized-bed riser by combining the two-fluid model with the EMMS approach, Industrial \& Engineering Chemistry Research, 43: 5548-61, 2004. 